\title{
Spatiotemporal Characteristics of the Pollution Reduction Effect of Differentiated Coordinated Development in the Yangtze River Economic Belt, China
}

\section{Li Xin Xiong ( $\nabla$ xionglixin@csu.edu.cn )}

Central South Forestry University: Central South University of Forestry and Technology

Jia Jun Ning

Central South University of Forestry and Technology

Yun He Dong

Central South Forestry University: Central South University of Forestry and Technology Meng Meng Dai

Central South Forestry University: Central South University of Forestry and Technology

\section{Research Article}

Keywords: Yangtze River Economic Belt, Regional coordinated development, Regional differentiation development, Pollution reduction, Heterogeneity

Posted Date: February 9th, 2021

DOI: https://doi.org/10.21203/rs.3.rs-160334/v1

License: (c) (i) This work is licensed under a Creative Commons Attribution 4.0 International License. Read Full License 


\title{
1 Spatiotemporal characteristics of the pollution reduction effect of differentiated
}

\section{2 coordinated development in the Yangtze River Economic Belt, China}

3 Li-Xin Xiong ${ }^{12} \cdot$ Jia-Jun Ning $^{1} \cdot$ Yun-He Dong ${ }^{1} \cdot$ Meng-Meng Dai $^{1}$

\begin{abstract}
The pollution reduction effect of regional development could be analyzed more comprehensively from the perspectives of coordinated development and differentiated development. Based on the theory of regional coordinated development, this paper used panel data for cities in the Yangtze River Economic Belt from 2008 to 2017, adopted the spatial autocorrelation method and spatial econometric model to analyze the spatial and temporal distribution pattern of environmental pollution emission, regional coordination and differentiated development degree in the Yangtze River Economic Belt, analyzed the impact of regional differentiated coordinated development on pollution emission reduction in local and surrounding cities, and discussed the spatial spillover effect of regional differentiated coordinated development on pollution emission and its boundary test. The results showed that (1) at the overall level of the Yangtze River Economic Belt, coordinated regional development and differentiated regional development have significantly reduced pollution emissions and present complementary effects on pollution emission reductions; (2) an obvious spatial spillover effect was observed for the impact of regional coordinated and differential development on pollution reduction, a negative spatial spillover coefficient was observed for different urban economic circles, and an obvious inverted Ushaped trend occurred in the impact degree with increasing distance, with a $500 \mathrm{~km}$ range of urban economic circles considered a turning point; and (3) a heterogeneity test used the three major regions and sub-cities of the Yangtze River Economic Belt to verify and analyze the impacts of regional coordinated and differential development on pollution emissions, which showed that there was obvious spatial heterogeneity at different levels. Based on the above results, policy suggestions for decreasing pollution emissions in the process of differentiated coordinated development of the Yangtze River Economic Belt were proposed.
\end{abstract}

Keywords Yangtze River Economic Belt - Regional coordinated development • Regional differentiation development $\cdot$ Pollution reduction $\cdot$ Heterogeneity

\section{Introduction}

In recent years, the National Development Plan proposed that the Yangtze River Economic Belt should be "jointly protected rather than developed" to not only achieve high-quality economic development but also to strengthen ecological and environmental protection to realize the coordinated development of the social economy, resources and
32 environment in the Yangtze River Basin. With the acceleration

33 of industrialization and urbanization, the problems of

34 environmental pollution and resource consumption in the

35 Yangtze River Economic Belt have become increasingly

36 serious, which seriously restricts social and economic

37 development. As a golden waterway with the largest traffic

38 volume in the world (LU 2018), the Yangtze River crosses the

39 eastern, central and western regions of China, and the regional

\footnotetext{
${ }^{1}$ Business School, Central South University of Forestry and Technology of China, Changsha 410004, China

${ }^{2}$ Laboratoire Genie Civil et geo-Environnement, Universite de Lille, Lille 59655, France

Corresponding author: Li-Xin Xiong (E-mail: xionglixin@csu.edu.cn)
} 


\section{Literature Review}

51 At present, energy conservation and emission reduction under 52 the concept of sustainable development have attracted

energy utilization methods, industrial structures and pollutant emission characteristics exhibit significant differences (Liu Yang and Chen 2016). Such unbalanced development may trigger vicious competition, hinder the free flow of market elements, and intensify pollution emissions. According to differences in the development of resource endowment among the Yangtze River Economic Belt cities, orderly and healthy competition in the market to promote industrial convergence and realize complementary advantages can provide new possibilities for energy conservation and emissions reduction. extensive attention from scholars (Wagner and Timmins 2009; Sueyoshi and Yuan 2017; Azizalrahman and Hasyimi 2019; Brown et al. 2020). Based on the new economic geography theory, this paper analyzes the effect of regional pollution emission reduction from the perspective of economic factor agglomeration. Lu et al. (2014) found that economic activity agglomeration is beneficial for reducing the intensity of industrial pollution emissions, and Zhang and Wang (2014) built a theoretical model to analyze the two-way interaction mechanism between economic agglomeration and environmental pollution. Economic aggregates can improve environmental pollution, and there were significant spatial spillover effects. Other studies also found that economic element agglomeration had a nonlinear effect on environmental pollution (Zhu et al. 2019; Giannadaki et al. 2018; Dauda et al. 2019) in different regions because of spatiotemporal heterogeneity. For example, Xu et al. (2012) found that the concentration of Foreign Direct Investment (FDIs) in China can reduce pollution emissions and the degree of influence is significantly different based on different sources. Yang (2015) found that industrial agglomeration of pollution discharge has inverted U-shaped nonlinear effects, namely, industrial agglomeration at a low level will increase environmental pollution and industrial agglomeration that exceeds a threshold will improve environmental pollution. Shao et al. (2019) found that the energy-saving and emissionreduction effects of economic agglomeration may have a significant "inverted N-type" curve relationship and an obvious spatiotemporal dependence. The relationship between economic factor agglomeration and environmental pollution emissions has not yet been determined. Moreover, differences also occur in the environmental spillover effects of economic factor agglomeration on pollution emissions in different regions. Previous studies have focused on analyzing the spatial spillover effects of regional agglomeration on pollution emissions from the overall level; however, the spatial spillover effects of regional agglomeration on pollution emissions within the scope of different urban agglomerations still need to be further explored.

Scholars have also studied environmental pollution emissions and their mechanisms from the perspective of regional integration. As market segmentation increases, the gap between regional pollution emissions and energy efficiency has widened (Li and Lin 2017; Hasanbeigi and Price 2015) When the degree of market segmentation exceeds a certain limit, regional trade barriers will form and regional development will be inhibited ( $\mathrm{Lu}$ and Chen 2009; Ramanathan and Feng 2009; Li et al. 2017). The spatial difference in the regional economic development level indirectly affects the effect of pollution reduction. He et al. (2016), Shen et al. (2017) and Zhang (2018) found that regional integration can promote the intensity of pollution reduction caused by convergence and improve environmental pollution. Based on the "Environmental Kuznets Curve Theory" in the environmental pollution of scale, structure and technology effect, Sun and Cheng (2019) discussed the intermediate mechanism underlying the regional integration pollution emission effect. On this basis, scholars have further studied the transfer of pollution emissions within a region. Dou and Cui (2018) analyzed the interprovincial pollution transfer in China from a macro perspective, and Zhao (2019) and You and Chen (2019) considered the expansion of the Yangtze

5 River Delta as the carrier of regional integration to test the pollution emission effect between the new cities in the Yangtze

River Delta and older cities. A number of studies have found unbalanced regional pollution emissions: in the process of industrial transfer, factor flow and spatial allocation and integration, industrial pollution tends to move and spread from regions with high development levels to those with low development levels. Although scholars have reached a 3 consensus on that regional integration promote the discharge 4 of environmental pollution, few studies have investigated the 5 pollution emission effect of regional differentiated 
126 development. Interregional urban integration is a process of 127 "seeking common ground while maintaining differences". 128 However, whether regional coordination and differentiated 129 development can reduce pollution emissions is not clear and 130 the mechanisms that lead to pollution emission reductions 131 have not been identified. Therefore, it is of great significance 132 to study the pollution emission effect from the perspective of 133 regional coordination and differentiated development.

134 This article mainly performs research from three aspects:

135 (1) based on the theory of regional coordinated development, 136 PM2.5 emissions are selected as pollution indicators according 137 to the regional coordination degree and differentiation to 138 discuss the effect of pollution reduction in the development 139 process of "seeking common ground while maintaining 140 differences" among regional cities; (2) the spatial panel Durbin 141 model is adopted to test the coordinated development of the 142 regional differentiation spatial spillover effect on pollution 143 emissions, inspect its spatial spillover boundary, and analyze 144 the change trend of spatial spillover effects as with increased 145 distance; and (3) a multiscale discussion is included on the 146 degree of differentiation and the temporal and spatial 147 differences of pollution emissions in the Yangtze River 148 Economic Belt and the spatial heterogeneity of the impact of 149 regional development on pollution emissions at different levels 150 is verified. The visualization analysis of spatial distribution is 151 carried out in combination with a spatial econometric model.

\section{Theoretical Mechanism}

153 According to the "Haken synergy theory", despite differences 154 in the characteristics of each city, there are interactional 155 relationships between cities, including coordination, 156 cooperation and competition, and mutual interference between 157 restricting elements (Haken 1983). Regional development 158 is a process from the integration of independent economic 159 entities into the whole economy, and it emphasizes the organic 160 combination of regional synergy and regional differentiation 161 (Li and Qi 2019; Liu et al. 2019). Regional economic factors 162 influence environmental pollution reduction based on the 163 regional synergy among cities as well as regional 164 differentiation. The development mechanism is shown in 165 Figure 1.

First, the efficiency of regional factors must be 167 coordinated to promote energy conservation and emission
168 reduction under regionally coordinated development. Along 169 with the construction of intercity transportation networks, the 170 development of information technology and the optimization 171 of regional spatial structures, capital flows, logistics, people 172 flows and information flows move at a high speed, thereby 173 reducing the cost waste caused by information asymmetry (Shi 174 et al. 2018; Lanzi et al. 2018). The sharing of infrastructure 175 and public resources can accelerate industrial agglomeration to 176 reduce the common production operation costs of enterprises 177 in the region and realize the effective allocation of resources 178 to reduce pollution emissions (Liu and $\mathrm{Wu}$ 2017; Yao et al. 179 2019). Second, the standardization of regional environmental 180 regulation should be promoted. By formulating new 181 environmental laws and regulations, local governments have 182 proposed new requirements in terms of emission standards, 183 product standards and product specifications. With the 184 intensified competition caused by homogenization among 185 enterprises, the rising cost of pollution control forces 186 enterprises to gradually turn to clean energy, accelerate 187 scientific and technological research and innovation and 188 reduce pollution emissions (Zhang et al. 2020). Moreover, the 189 process of the transferring regional labor factors, the 190 environmental protection concept of immigrants transferred to 191 areas with stricter environmental supervision is increasingly 192 strengthened, which promotes cross-regional dissemination 193 and cultivation of green environment concepts. Third, 194 interregional cooperation and complementarity of resource 195 elements should be promoted. Market segmentation will 196 intensify tax competition among cities, and fiscal 197 decentralization and promotion and assessment by local 198 officials will lead to a "race to the bottom" phenomenon, in 199 which foreign investment will be introduced at the expense of 200 the ecological environment and regions with low economic 201 development will become a "pollution paradise"(Baghdadi et 202 al. 2013), which will have a negative impact on the overall 203 ecological environment. By promoting environmental 204 performance as an important indicator for performance 205 appraisals, regions have focused more attention on overall 206 interests. Local governments will abandon "local 207 protectionism" in favor of resource complementarity, mutual 208 assistance, benefit sharing, and coordinated relationships 209 between economic and environmental development. Moreover, 210 regional cooperation and exchanges accelerate the transfer of 211 economic factors, and cross-regional employment of the 
212 population reflects the spillover effect of knowledge and 213 improves the efficiency of production factors.

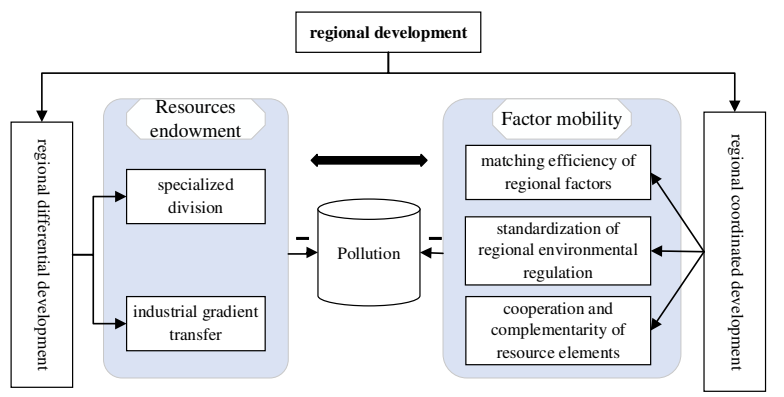

215 Fig 1 Regional differentiation and coordinated development of

\section{6 pollution emission reduction mechanisms}

217 Energy conservation and emission reductions under 218 regionally differentiated development benefit from the 219 specialized division of labor between regions, with different 220 regions relying on their own resource factor endowment, 221 which generates different comparative advantages, develops

\section{Econometric model setting}

\section{Establishment of spatial econometric model}

242 The STIRPAT model is widely used in environmental 243 economics, and the original IPAT model can extend the 244 random variable (Dietz and Rosa 1994). In this study, 245 explanatory variables, such as the degree of regional
246 coordinated development and the degree of regional 247 differentiated development, are added, and they are expressed 248 are as follows:
250

249

251

252

253

254

255

256

257

258

259

260

261

262

$$
\operatorname{lnpollu}_{i t}=\alpha_{0}+\alpha_{1} \operatorname{lnec}_{i t}+\alpha_{2} \operatorname{lnec}_{i t} * \ln d v_{i t}+\alpha_{3} \ln d v_{i t}+
$$$$
\alpha_{4} X_{i t}+\varepsilon_{i t}
$$

where lnpollu $_{i t}$ represents the amount of pollution emitted by each city; $\operatorname{lnec}_{i t}$ is the regional synergetic degree of each city and other cities in the Yangtze River Economic Belt; $\operatorname{lnd} v_{i t}$ is the degree of regional differentiation between each city and other cities in the Yangtze River Economic Belt; $\operatorname{lne} c_{i t} * \ln d v_{i t}$ is the interaction term of regional cooperation degree and regional differentiation degree; $X_{i t}$ is the control variable; and $\varepsilon_{i t}$ is the random error term.

According to the above model, a further judgment is made as follows: according to the criteria of the spatial measurement model, the Hausman test, LR test, WALD test and LM test should be used to further determine the model. The verification results are shown in Table 1. In the Hausmann test results, $c h i_{2}$ is negative. The null hypothesis is accepted, and a random effect is selected. The LM test results showed that all four tests were significant at the $1 \%$ level, indicating that the spatial Durbin model (SDM) had a better fitting effect. To further validate the conclusions, the corresponding Wald spatial lag after inspection and spatial error analysis, and LR space lag inspection and space error analysis are under the level of $1 \%$ by significance test, showing that the spatial lag model (SAR) and spatial error model (SEM) are appropriate. In conclusion, the spatial Durbin model (SDM) combining the two spatial models should be used to analyze the regional synergy differentiation development impact on pollution reduction.

In summary, the expression of the model is as follows: lnpollu $_{i t}=\beta_{0}+\rho \sum_{j=1}^{N} W_{i t}$ lnpollu $_{i t}+\beta_{1}$ lnec $_{i t}+\beta_{2} \operatorname{lnec}_{i t} *$ $\operatorname{lnd} v_{i t}+\beta_{3} \ln d v_{i t}+\gamma_{1} \sum_{j=1}^{N} W_{i t} \operatorname{lnec}_{i t}+\gamma_{2} \sum_{j=1}^{N} W_{i t} \operatorname{lnec}_{i t} *$ $\operatorname{lnd} v_{i t}+\gamma_{3} \sum_{j=1}^{N} W_{i t} \operatorname{lnd} v_{i t}+\beta_{4} X_{i t}+\gamma_{4} \sum_{j=1}^{N} W_{i t} X_{i t}+\varepsilon_{i t}$ (2)

where $W_{i t}$ is the space weight; $\rho$ represents the spatial autoregression coefficient; and $\gamma$ represents the space overflow coefficient.

\section{Data processing}

7 Based on data availability, this paper selects the data of 105 8 cities above the prefecture level in the Yangtze River 
289 Economic Belt from 2008 to 2017 and replaces some missing

290 values with a linear interpolation or the average growth rate

291 method. Descriptive statistics of the main variables are shown

292 in Table 2.

293 Table 1 Space metrology test

\begin{tabular}{cccc}
\hline \multicolumn{2}{c}{ Test } & Results & P-value \\
\hline \multirow{3}{*}{ Hausman test } & -21.7 & - \\
& Test for SAR & 44.16 & 0.000 \\
& Test for SEM & 36.37 & 0.000 \\
\multirow{3}{*}{ LR test } & Test for SAR & 49.5 & 0.000 \\
& Test for SEM & 143.93 & 0.000 \\
& LMerr & 858.732 & 0.000 \\
\multirow{3}{*}{ LM test } & LMlag & 136.459 & 0.000 \\
& R-LMerr & 815.627 & 0.000 \\
& R-LMlag & 93.354 & 0.000 \\
\hline
\end{tabular}

294

295 Table 2 Descriptive statistical analysis

\begin{tabular}{cccccc}
\hline Variable & $\mathrm{N}$ & Mean & Std. Dev. & Min & Max \\
\hline pollu & 1050 & 47.15 & 13.91 & 10.88 & 75.62 \\
ec & 1050 & 68695.37 & 90908.92 & 965.95 & 896677.9 \\
dv & 1050 & 322.14 & 18.42 & 281.6 & 397.44 \\
Fdis & 1050 & 329221 & $2.4 \mathrm{E}+06$ & 3 & $3.45 \mathrm{E}+07$ \\
Gov & 1050 & 0.22 & 0.18 & 0.02 & 2.03 \\
Dens & 1050 & 0.83 & 10.26 & 0.01 & 143.42 \\
Tc & 1050 & 655.85 & 1809.74 & 1 & 20567 \\
Struct & 1050 & 0.92 & 0.49 & 0.24 & 4.92 \\
Mp & 1050 & 2540.41 & 4285.01 & 98.89 & 48309.4 \\
\hline
\end{tabular}

296 Core variables

297 Regional synergy $(e c)$. The higher the intercity connection, the

298 higher the degree of regional cooperative development; and

299 the greater the geographical distance between cities, the lower

300 the degree of collaborative development between cities ( $\mathrm{Li}$ and

301 Zeng 2016). The modified gravity model was used to calculate

302 the degree of regional collaborative development between

303 cities and 104 other cities in the Yangtze River Economic Belt:

$304 e c_{i t}=\sum_{j=1}^{104} X_{i j t} *$

$305 \sqrt{R_{i t} * G D P_{i t}} * \sqrt{R_{j t} * G D P_{j t}} / D_{i j}^{2}$

306

$307=\frac{G D P_{i t}}{\left(G D P_{i t}+G D P_{j t}\right)}$

308 where $i$ represents the city, $j$ represents other cities in 309 the Yangtze River Economic belt except the city, $t$ represents
310 the year, $R_{t}$ is the population of the city at the end of $t, G D P_{t}$

311 is the GDP in year $t$, and $D_{i j}$ represents the geographical

312 distance between city $i$ and city $j$.

313 Regional differentiation $(d v)$. The degree of difference

314 between city $i$ and 104 other cities in the Yangtze River

315 Economic Belt in year $t$ was determined by using the method

316 of Liu and $\mathrm{Wu}$ (2017). The specific calculation formula is as

317 follows:

$318 d v_{i t}=\sum_{j=1}^{104} \sum_{x=1}^{11} a b s\left(D_{i t}^{x} / D_{i t}-D_{j t}^{x} / D_{j t}\right)$

319 where $D_{t}^{x}$ represents the employed population of the

320 city in $x$ industry in year $t$ (the number of employees in 11

321 industries selected to calculate regional differentiation because

322 the number of employees in different industries is frequently

323 missing from statistical yearbooks); and $D_{i t}$ and $D_{j t}$

324 represent the total number of employees of 11 industries in $i$

325 and $j$ cities in year $t$.

326 Pollution degree (pollu) is an index of the serious effect 327 of air pollution on environmental quality, which has attracted 328 wide attention from all walks of life in recent years. Moreover, 329 air pollutants have strong mobility in the region, and the effect 330 of spatial spillover effects is better. Therefore, the annual 331 average PM2.5 concentration is selected as a pollution 332 indicator to measure the degree of regional pollution.

\section{Control variables}

334 Foreign direct investment (FDIs). The environmental protection technology of foreign enterprises is more advanced, and the associated environmental protection awareness is strong. The introduction of foreign enterprises is conducive to reducing pollution emissions, and urban foreign direct investment is considered a measure of FDIs (Xu and Deng 2012). Government intervention (gov) is considered an index of local governments' rational allocation of resources according to local information and the emission intensity level

343 of pollution in the current year to reduce pollution emissions.

344 The level of government intervention is calculated by dividing 345 government fiscal expenditure by GDP (Sun and Cheng 2019).

346 Energy efficiency (eng) is an index of how improved energy 347 efficiency can reduce pollution emissions (Zhang et al. 2013), 348 and it is measured by the ratio of GDP to local electricity 349 consumption. Infrastruteture (inf) is an index indicating that 350 more complete infrastructure corresponds to lower costs and 351 less pollution emissions, and it is measured by per capita urban 
road area (Zhao 2019). Population density (dens) is an important factor that affects regional pollution benefits, and it is measured using the local area of the city divided by its population, namely, the number of people per square kilometer

\section{Pollution global spatial correlation}

388 Moran's I index of pollutant emissions in the Yangtze River 389 Economic Belt from 2008 to 2017 was between 0.35 and 0.49; 390 thus, both years passed the significance test at the $1 \%$ level and 391 were positive, indicating that there is a positive spatial city in that year, and it is used to measure the technological development and innovation level of the region. A greater number of patented technologies corresponds to a higher technological innovation level of the city. Industrial inspection (struct) is an index of the proportion of the output of tertiary industry in the output of the secondary industry in each prefecture-level city. A larger proportion indicates that the industrial structure transformation and upgrading are fast and that the degree of optimized allocation of factors is high.

\section{Spatial-temporal characteristics}

\section{pollution emissions}

This article analyzes the temporal and spatial differences in regional coordinated development, differentiated development and pollution emissions in the Yangtze River Economic Belt and obtains the temporal and spatial distribution characteristics of each element in the Yangtze River Economic Belt. Global Moran's I analyzes the spatial correlation of global pollution in the Yangtze River Economic Belt; the local spatial correlation index Getis-Ord $G^{*}$ judges the local distribution of high-value pollution agglomeration areas and low-level pollution agglomeration areas in the Yangtze River Economic Belt. The spatial correlation index is divided into four points according to the self-breaking point. The method is divided into hot spot areas, sub-hot spot areas, sub-cold spot areas and cold spot areas. correlation of pollution emissions in the Yangtze River Economic Belt. That is, areas with high (low) pollution levels are adjacent to areas with high (low) pollution levels. The data is shown in Table 3. Moran's I index of pollution indicators varies greatly from 2008 to 2013, indicating that the regional pollution concentration changes greatly. Moran's I index remained stable from 2013 to 2017, indicating that pollution emissions have little spatial variation.

01 Yangtze River Economic Belt from 2008 to 2017

\begin{tabular}{ccccc}
\hline Year & Moran's I & Variance & Z-value & P-value \\
\hline 2008 & 0.391 & 0.032 & 12.507 & 0.001 \\
2009 & 0.401 & 0.032 & 12.758 & 0.001 \\
2010 & 0.366 & 0.030 & 12.457 & 0.001 \\
2011 & 0.351 & 0.032 & 11.272 & 0.001 \\
2012 & 0.386 & 0.032 & 12.303 & 0.001 \\
2013 & 0.367 & 0.032 & 12.325 & 0.001 \\
2014 & 0.459 & 0.032 & 14.503 & 0.001 \\
2015 & 0.462 & 0.032 & 14.568 & 0.001 \\
2016 & 0.442 & 0.032 & 24.227 & 0.001 \\
2017 & 0.495 & 0.031 & 16.327 & 0.001 \\
\hline
\end{tabular}

\section{Local temporal and spatial distribution differences}

403 From 2008 to 2012, the "clustering" of pollution emissions in 404 the Yangtze River Economic Belt became more obvious, thus 405 showing a spatial pattern of "high in the center and low in the 406 surrounding area". As shown in Figure 2 and Figure 3, 407 agglomeration "hot spots" mainly occur in the northern region 408 of the lower reaches of the Yangtze River and agglomeration 409 "cold spots" mainly occur in the southwestern region of the 410 upper reaches of the Yangtze River. Highly polluted areas are 411 mainly concentrated in the Sichuan-Chongqing urban 412 agglomeration, Wuhan City cycle, Changsha-Zhuzhou413 Xiangtan urban agglomeration area, northern Anhui, and 414 northern Jiangsu. The pollution levels in the middle reaches of 415 the Yangtze River and the Sichuan-Chongqing urban 416 agglomeration have increased significantly. The area of 417 moderately polluted areas has shrunk, thus forming small areas 418 in Hunan, Sichuan, Anhui, and Jiangsu. The low-pollution 419 areas are mainly concentrated in the southern areas of the 420 middle and lower reaches of the Yangtze River Economic Belt, 421 and the pollution scope has experienced little change. The 422 southwest region centered around Kunming maintains a low 423 pollution state, while the spatial distribution pattern of 
424 pollution has undergone significant changes from 2012 to 425 2017. The overall ecological environment of the Yangtze River Economic Belt has been greatly improved, and the degree of pollution in the region has shown an increasing trend from north to south. High-pollution and higher-pollution areas are distributed in the northern part of the lower reaches, such as the Sichuan-Chongqing urban agglomeration, the Yangtze River Delta, and the Yangtze River middle-reach urban agglomeration, indicating that the regional integration of urban

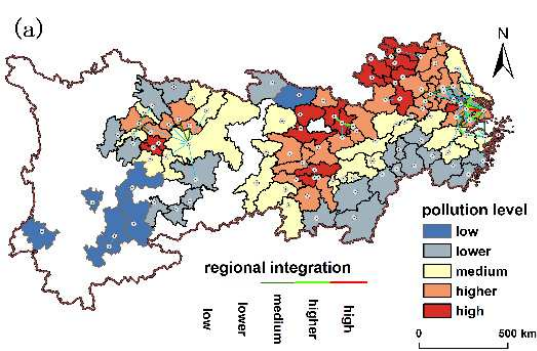
in 2008; b: in 2012; c: in 2017)

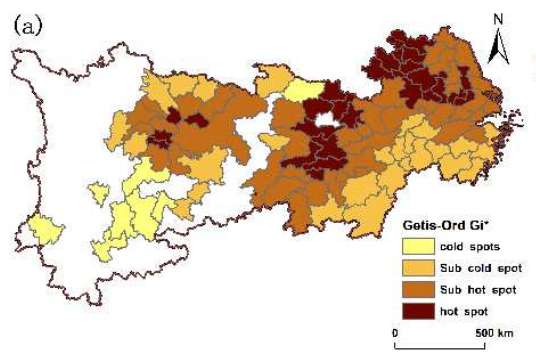

Economic Belt is different (a: in 2008; b: in 2012; c: in 2017)

This article further analyzed the degree of regional differentiation development. As shown in Figure 4, the overall degree of regional differentiation in the Yangtze River Economic Belt from 2008 to 2017 showed a significant downward trend. Compared with regions in the middle and upper reaches of the Yangtze River, the lower reaches of the Yangtze River have a higher degree of differentiation. At the same time, the degree of regional coordination between cities in the lower reaches of the Yangtze River is also high, which further shows that the coordinated development and differentiated development of the region are not in conflict and jointly promote regional development. The provinces in the upper reaches of the Yangtze River are less differentiated, and Hubei Province in the middle reaches of the Yangtze River has a high degree of regional differentiation. 465

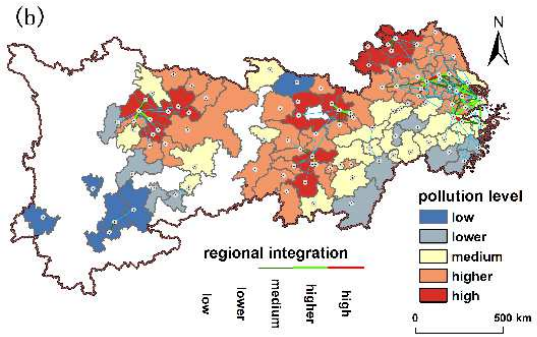

433 agglomerations strengthens the degree of intercity regional connections. The degree of coordination between the north and south in the upper, middle, and lower reaches of the Yangtze River Economic Belt has also been continuously strengthened.

437 For example, the collaboration degree of the middle reaches of 438 the Changsha-Zhuzhou-Xiangtan urban agglomeration and the 439 Wuhan City cycle, the upstream area Sichuan-Chongqing 440 urban agglomeration and Guizhou Province is gradually 441 becoming denser.

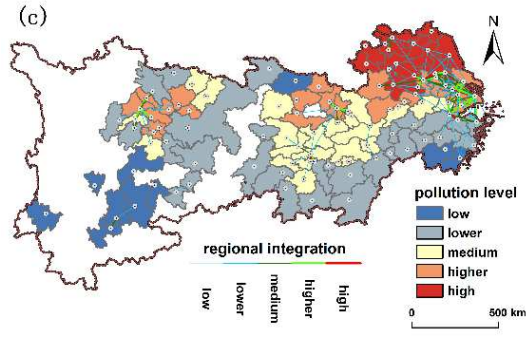

Fig 2 Spatial and temporal differentiation of pollution emissions in the coordinated development of the Yangtze Economic Belt (a:
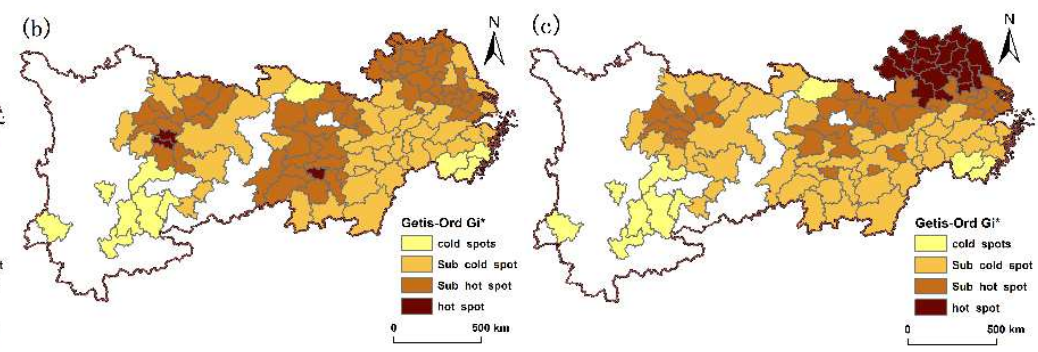

Fig 3 Spatial and temporal differentiation map of pollution concentration hotspots and cold spots cities in the Yangtze River

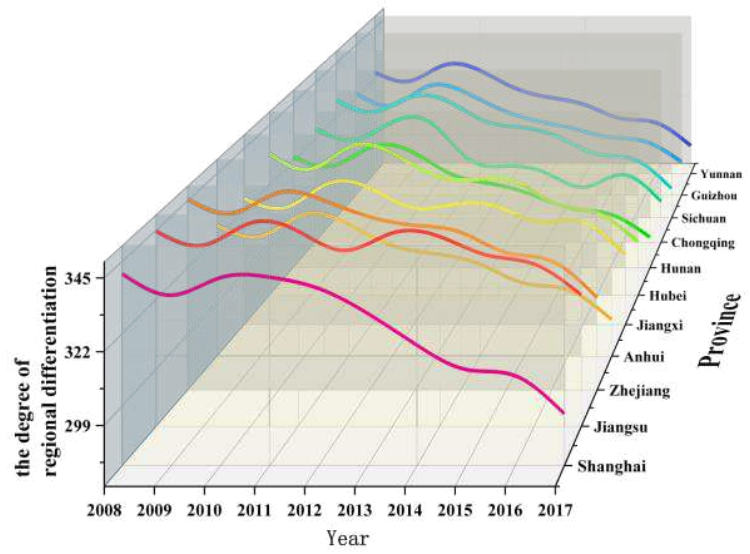

464 Fig 4 Development degree of different provinces and cities in the Yangtze River Economic Belt is different 
differential

\section{8 development}

\section{Benchmark regression analysis}

470 To ensure the robustness of the estimation results of various 471 variables, this paper adopts the regression analysis of four 472 types of spatial measurement models. The regression results 473 are shown in Table 4. The coefficient signs of the spatial 474 measurement models are completely consistent, and the 475 regression coefficients of the core variables on local 476 pollution emissions pass the 5\% significance level test, 477 indicating that the regression results are relatively robust. 478 The spatial autoregressive coefficients of pollution 479 emissions are positive, and all passed the $1 \%$ significance 480 test, indicating that the aggravation of pollution emissions 481 from surrounding cities will increase local urban pollution 482 emissions. In other words, pollution emissions in the region between regional coordinated and regional differential development is positive, and both pass the $5 \%$ significance

Table 4 Space panel measurement results
496 test. These findings show that regional coordinated 497 development and regional differentiated development 498 complement jointly promote pollution emission reduction, 499 which has a significant effect on pollution reduction. The 500 regression coefficient of the spatial lag variable is negative, 501 indicating that the coordinated development and 502 differentiated development of the local city have a negative 503 impact on neighboring pollution reduction.

\section{Spatial effect trend of different urban economic 505 circles}

506 A previous article analyzed the significant pollution 507 reduction effects of regionally differentiated and coordinated 508 development and then used the indirect effects of the random 509 effect spatial Durbin model for further analysis (Bai et al. 510 2017). The "Circular Cumulative Causation Theory" states 511 that regional development is not uniformly diffused. Usually, 512 the "central zone" begins to accumulate advantages first and 513 gradually spreads outward through different channels 514 (Krugman, 1991). The Yangtze River Economic Belt spans a 515 wide range, and the impact of regional factor flow on 516 environmental pollution has spatial spillover effects. 517 Drawing lessons from the methods of Yuan et al. (2019) and 518 Dong and Wang (2019), different thresholds were set and a 519 spatial weight matrix was established to discuss the spatial 520 spillover effects of regional coordinated and differentiated 521 development on pollution emissions within the distance of 522 different urban agglomerations.

523 The spatial spillover coefficient passed the 10\% 524 significance test within the range of the urban economic 525 groups of 100 to 525 kilometers and became no longer 526 significant after exceeding a range of 525 kilometers. The 527 results are shown in Figure 5.

\begin{tabular}{|c|c|c|c|c|c|c|c|c|}
\hline \multirow{3}{*}{ Variable } & \multicolumn{2}{|c|}{ SEM } & \multicolumn{2}{|c|}{ SAR } & \multicolumn{2}{|c|}{ SAC } & \multicolumn{2}{|c|}{ SDM } \\
\hline & (1) & (2) & (3) & (4) & (5) & (6) & (7) & (8) \\
\hline & Inpollu & Inpollu & Inpollu & Inpollu & Inpollu & Inpollu & Inpollu & lnpollu \\
\hline \multicolumn{9}{|l|}{ Local } \\
\hline \multirow[t]{2}{*}{$\operatorname{lnec}$} & $0.732^{* *}$ & $0.701^{* *}$ & $0.992 * * *$ & $0.887^{* * * *}$ & $0.892^{* * * *}$ & $0.703 * * *$ & $0.809^{* *}$ & $-0.955^{* *}$ \\
\hline & $(0.276)$ & $(0.275)$ & $(0.2450)$ & $(0.248)$ & $(0.166)$ & $(0.199)$ & $(0.289)$ & $(0.292)$ \\
\hline $\operatorname{lndv}$ & $1.229^{* *}$ & $1.220^{* *}$ & $1.697 * * *$ & $1.517 * *$ & $1.699 * * *$ & $1.256^{* * *}$ & $1.416^{* *}$ & $1.787 * * *$ \\
\hline
\end{tabular}




\begin{tabular}{|c|c|c|c|c|c|c|c|c|}
\hline & $(0.519)$ & $(0.517)$ & $(0.445)$ & $(0.463)$ & $(0.302)$ & $(0.370)$ & $(0.545)$ & $(0.554)$ \\
\hline \multirow[t]{2}{*}{ Lnec*Indv } & $0.130 * *$ & $0.126^{* *}$ & $0.172 * * *$ & $0.155^{* * *}$ & $0.160 * * *$ & $0.130 * * *$ & $0.148^{* *}$ & $0.174 * * *$ \\
\hline & $(0.048)$ & $(0.048)$ & $(0.042)$ & $(0.043)$ & $(0.029)$ & $(0.035)$ & $(0.050)$ & $(0.050)$ \\
\hline \multicolumn{9}{|l|}{ Neighborhood } \\
\hline \multirow[t]{2}{*}{ lnec } & & & & & & & 0.094 & 0.140 \\
\hline & & & & & & & $(0.396)$ & $(0.412)$ \\
\hline \multirow[t]{2}{*}{$\operatorname{lndv}$} & & & & & & & 0.142 & 0.446 \\
\hline & & & & & & & $(0.712)$ & $(0.734)$ \\
\hline \multirow[t]{2}{*}{$\operatorname{lnec} * \operatorname{lndv}$} & & & & & & & 0.007 & 0.025 \\
\hline & & & & & & & $(0.069)$ & $(0.072)$ \\
\hline \multirow[t]{2}{*}{ rho } & $0.831^{* * * *}$ & $0.836^{* * *}$ & $0.899^{* * *}$ & $0.896^{\text {**** }}$ & $1.106^{* * *}$ & $0.925 * * *$ & $0.895^{* * *}$ & $0.882^{* * * *}$ \\
\hline & $(0.024)$ & $(0.023)$ & $(0.016)$ & $(0.016)$ & $(0.011)$ & $(0.017)$ & $(0.016)$ & $(0.018)$ \\
\hline $\begin{array}{l}\text { Control } \\
\text { variables }\end{array}$ & $\mathrm{N}$ & $\mathrm{Y}$ & $\mathrm{N}$ & $\mathrm{Y}$ & $\mathrm{N}$ & $\mathrm{Y}$ & $\mathrm{N}$ & $\mathrm{Y}$ \\
\hline $\mathrm{N}$ & 1050 & 1050 & 1050 & 1050 & 1050 & 1050 & 1050 & 1050 \\
\hline LOG L & 1603.32 & 1611.14 & 1276.78 & 1282.98 & 1639.9 & 1623.76 & 1284.61 & 1307.73 \\
\hline
\end{tabular}

Note: 1$)^{* * *},{ }^{* *}$, and * passed the significance level test at $1 \%, 5 \%$, and $10 \%$, respectively. 2) The value of $t$ is in brackets.

Regional coordinated development and regional differentiated development have exactly the same impact on pollution emissions. As the scope of urban agglomerations expands, differentiated coordinated development has always had a negative impact on pollution emissions from surrounding cities, which further shows that regional coordinated development and differential development complement each other, thereby promoting pollution emissions from surrounding cities. The pollution reduction effect of regionally differentiated and coordinated development shows an inverted $U$ shaped trend. That is, within a certain geographic distance, the spillover and emission reduction of regionally coordinated pollution will first increase and then decrease. Specifically, in the range of 100-300 kilometers, regional coordinated differential development has relatively little impact on the pollution emissions of surrounding cities, indicating that the efficiency of pollution reduction in the area of 100-300 kilometers is relatively low. When the spatial distance range exceeds 300 kilometers, as the distance range expands, the impact of regionally differentiated development on the pollution reduction effect of surrounding cities is greatly strengthened because the expansion of the spatial range of urban agglomerations is more conducive to local labor cooperation to promote technology spillovers and the upgrade and transfer of industry. A peak is reached within 500 kilometers, and the pollution reduction effect continues to weaken after
557500 kilometers until the spatial spillover effect is no longer 558 significant. In summary, the verification shows that within 559 different distances, regional coordinated and differentiated 560 development has different spatial spillover effects on 561 pollution reduction.

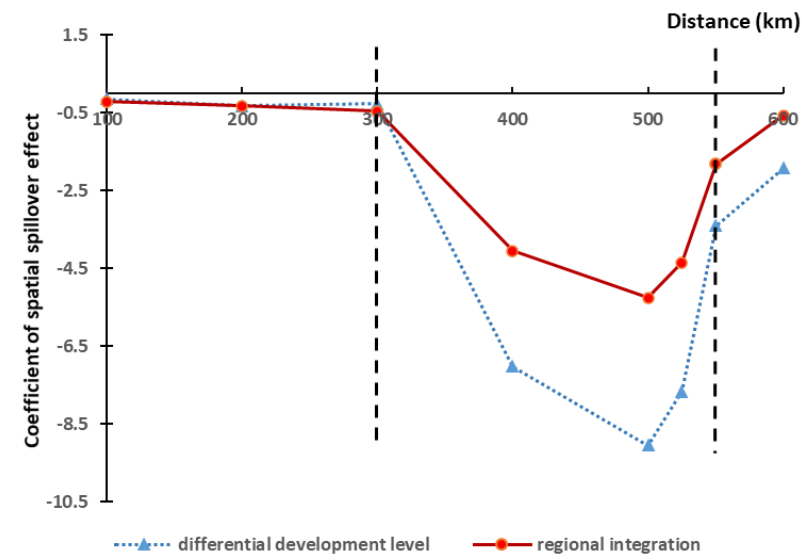

563 Fig 5 Spillover coefficient of differentiated coordinated

564 development space in different urban areas

\section{Analysis of the heterogeneity of the three major 566 regions of the Yangtze River Economic Belt}

567 The regression results at the overall level of the Yangtze 568 River Economic Belt indicate that the differential and 569 coordinated development of the Yangtze River Economic 570 Belt has promoted the reduction of pollution and further 571 indicate the impact of regional differentiated coordinated 572 development on pollution emissions in the lower, middle and 
upper reaches of the Yangtze River Economic Belt. The

574 regression results are shown in Table 5. The coefficient of 575 regional coordinated development and differential 576 development in the lower reaches of the Yangtze River is 577 positive, and the coefficient of the interaction term of the two 578 is negative and passes the $10 \%$ significance test. The sign of 579 the spatial lag coefficient is the opposite. It promotes the 580 reduction of pollution emissions in the surrounding areas.

581 The coefficients of regional coordinated development and

582 differentiated development in the upper and middle reaches 583 of the Yangtze River are both negative and pass the $10 \%$ 584 significance test, and the coefficient of the interaction term 585 is positive and passes the $10 \%$ significance test, indicating 586 that the upper and middle reaches of the two major regions 587 of the Yangtze River Economic Belt promote pollution 588 reduction in the process of differentiated and coordinated 589 development. The pollution reduction effect of the upper and 590 middle reaches of the Yangtze River is consistent with the 591 overall level of the Yangtze River Economic Belt, and the 592 intensity of the reduction effect of coordinated and 593 differential development in the upper reaches of the Yangtze 594 River is significantly greater than that of the middle reaches 595 of the Yangtze River.

596 Table 5 Regression results of the spatial econometric model in 597 different regions of the Yangtze River Economic Belt

\begin{tabular}{|c|c|c|c|c|}
\hline city & Whole & Upper & Middle & Lower \\
\hline \multicolumn{5}{|l|}{ Local } \\
\hline \multirow[t]{2}{*}{$\operatorname{lnec}$} & $0.955^{* *}$ & $1.119^{*}$ & $0.651 *$ & $1.066^{* *}$ \\
\hline & $(0.292)$ & $(0.600)$ & $(0.355)$ & $(0.380)$ \\
\hline \multirow[t]{2}{*}{$\operatorname{lndv}$} & $1.787 * *$ & $1.571 *$ & $1.157 *$ & $1.953 * *$ \\
\hline & $(0.554)$ & $(0.951)$ & $(0.672)$ & $(0.745)$ \\
\hline \multirow[t]{2}{*}{$\operatorname{lnec} * \operatorname{lndv}$} & $0.174 * * *$ & $0.191 *$ & $0.114^{*}$ & $0.175^{* *}$ \\
\hline & $(0.050)$ & $(0.105)$ & $(0.061)$ & $(0.065)$ \\
\hline \multicolumn{5}{|l|}{ Neighborhood } \\
\hline \multirow[t]{2}{*}{$\operatorname{lnec}$} & 0.140 & 0.322 & $0.322 * * *$ & $1.791 * *$ \\
\hline & $(0.412)$ & $(0.212)$ & $(0.098)$ & $(0.618)$ \\
\hline \multirow[t]{2}{*}{$\operatorname{lndv}$} & 0.446 & $0.345^{* * *} *$ & $0.604 * * *$ & $3.324 * *$ \\
\hline & $(0.734)$ & $(0.064)$ & $(0.044)$ & $(1.210)$ \\
\hline \multirow[t]{2}{*}{$\operatorname{lnec} * \operatorname{lndv}$} & 0.025 & $0.069^{*}$ & $0.054 * *$ & $0.303 * *$ \\
\hline & $(0.072)$ & $(0.035)$ & $(0.017)$ & $(0.106)$ \\
\hline \multirow[t]{2}{*}{ rho } & $0.882 * * *$ & $0.724 * * *$ & $0.880^{* * *}$ & $0.916^{* * *}$ \\
\hline & $(0.018)$ & $(0.039)$ & $(0.021)$ & $(0.014)$ \\
\hline $\begin{array}{l}\text { Control } \\
\text { variables }\end{array}$ & $\mathrm{Y}$ & $\mathrm{Y}$ & $\mathrm{Y}$ & $\mathrm{Y}$ \\
\hline
\end{tabular}

\section{Heterogeneity analysis of cities of different sizes}

599 To further test the spatial heterogeneity of the impact of the 600 differential and coordinated development of the Yangtze 601 River Economic Belt on pollution emissions at the level of 602 different cities, referring to the methods of Yu and Jin (2014),

603 Feng and Wang (2019), the belt cities are divided into four 604 categories for the regression analysis. The results are shown 605 in Table 6.

606 Table 6 Regression results of the scale spatial econometric 607 model

\begin{tabular}{|c|c|c|c|c|}
\hline City & Mega-city & $\begin{array}{r}\text { Large } \\
\text { sized }\end{array}$ & $\begin{array}{c}\text { Medium } \\
\text { sized }\end{array}$ & $\begin{array}{l}\text { Small } \\
\text { sized }\end{array}$ \\
\hline \multicolumn{5}{|l|}{ Local } \\
\hline \multirow[t]{2}{*}{ Inec } & $2.269^{*}$ & $1.728^{* *}$ & $2.072 * *$ & 0.163 \\
\hline & (1.233) & $(0.723)$ & $(0.670)$ & $(0.705)$ \\
\hline \multirow[t]{2}{*}{$\operatorname{lndv}$} & $5.032 * *$ & $3.139 * *$ & $4.013^{* *}$ & 0.504 \\
\hline & $(2.516)$ & $(1.371)$ & $(1.282)$ & $(1.146)$ \\
\hline \multirow[t]{2}{*}{$\operatorname{lnec} * \operatorname{lndv}$} & $0.400^{*}$ & $0.299 * *$ & $0.377^{* *}$ & 0.012 \\
\hline & $(0.214)$ & $(0.125)$ & $(0.116)$ & $(0.121)$ \\
\hline \multicolumn{5}{|l|}{ Neighborhood } \\
\hline \multirow[t]{2}{*}{ lnec } & $34.032 * * *$ & $1.679^{*}$ & $2.480 * *$ & 0.900 \\
\hline & $(6.106)$ & (1.008) & $(0.970)$ & (1.124) \\
\hline \multirow[t]{2}{*}{$\operatorname{lndv}$} & $61.984 * * *$ & $3.475^{*}$ & $5.487 * *$ & 1.227 \\
\hline & (11.573) & (1.929) & $(1.850)$ & (1.568) \\
\hline \multirow[t]{2}{*}{$\operatorname{lnec} * \operatorname{lndv}$} & $5.899 * * * *$ & $0.291 *$ & $0.441 * *$ & 0.116 \\
\hline & $(1.068)$ & $(0.175)$ & $(0.170)$ & $(0.192)$ \\
\hline \multirow[t]{2}{*}{ rho } & $0.219^{*}$ & $0.764 * * *$ & $0.616^{* * *}$ & $0.410^{* * *}$ \\
\hline & $(0.131)$ & $(0.028)$ & $(0.040)$ & $(0.073)$ \\
\hline Zontrol variables & $\mathrm{Y}$ & $\mathrm{Y}$ & $\mathrm{Y}$ & $\mathrm{Y}$ \\
\hline $\mathrm{N}$ & 270 & 340 & 310 & 130 \\
\hline
\end{tabular}

The signs of the coefficients of the coordinated 609 development of mega cities on the pollution of the city and 610 surrounding cities are all negative, with both passing the $10 \%$ 611 significance level test, and the coefficients of the two 612 interaction terms are both positive. This finding shows that 613 the coordinated and differential development of mega cities 614 not only promotes the reduction of pollution emissions in the 615 local city but also has spatial spillover effects to reduce 616 pollution emissions from surrounding cities, thus exerting 617 the "scale effect" of mega cities, saving resources and 618 reducing pollution emissions. The results of the coefficients 
619 for large and medium sized cities are similar. The impact of 620 regional coordinated development and regionally 621 differentiated development on local pollution emissions 622 passes the $10 \%$ significance level test, and the coefficient 623 sign is negative; however, the coefficients of the two on the 624 pollution emissions of the surrounding cities are positive and 625 passed the $10 \%$ significance test. This finding shows that the 626 coordinated development of large and medium sized cities 627 has promoted the reduction of pollution emissions in local 628 cities. The coefficients of regional coordinated development 629 and regional differential development in small cities have 630 failed the $10 \%$ significance level test, which may be due to 631 the limited spatial scope and low interregional collaboration 632 efficiency. Thus, the differential and coordinated 633 development of small cities has a negative impact on 634 pollution reduction.

\section{Conclusion}

636 Based on the theory of regional coordinated development, 637 this paper uses panel data of prefecture level cities in the 638 Yangtze River Economic Belt from 2008 to 2017 to analyze 639 the degree of regional coordinated development, the degree 640 of differentiated development, and the temporal and spatial 641 distribution pattern of pollution emissions in the Yangtze 642 River Economic Belt. Based on the Durbin model, this paper 643 used the STIRPAT model to analyze the impact of regional 644 differentiation and coordinated development on pollution 645 emissions and its spatial spillover effects. The analysis 646 results show the following.

647 At the overall level of the Yangtze River Economic Belt, 648 regional differential and coordinated development promoted 649 pollution reduction and improved the ecological 650 environment of the Yangtze River Economic Belt. The 651 effects of regional coordinated development and differential 652 development on pollution emissions are complementary. 653 Regional coordinated and differential development also has 654 a spatial spillover effect on pollution reduction. This effect 655 shows an obvious inverted $U$ shaped trend, with 500 656 kilometers representing the turning point, and the distance 657 range will reduce pollution in the surrounding area before 658 reaching the turning point. The impact continues to rise, 659 although after reaching the turning point, the impact 660 continues to decline and its effect is no longer significant.
661 The heterogeneity test shows that the differential and 662 coordinated development of the middle reaches of the 663 Yangtze River at the three major regional levels of the 664 Yangtze River Economic Belt promotes pollution reduction 665 in local and surrounding cities. At the city level, the 666 differentiated and coordinated development of mega cities 667 promotes the development of the city and the surrounding 668 cities. The coordinated development of large and medium 669 sized urban areas promotes the reduction of local urban 670 pollution emissions and aggravates the pollution emissions 671 of surrounding cities. The differential and coordinated 672 development of small cities does not have a significant 673 impact on pollution emissions.

674 Based on the above conclusions, in the process of 675 differentiated and coordinated development of the Yangtze

676 River Economic Belt, the following policy recommendations
677 678 679 680 681 682 683 684 685 686 687 688 689 690 691 692 693 694 695 are proposed to suppress pollution emissions.

First, the government should acknowledge the synergy among regional cities and strengthen cooperation in regional pollution control. Environmental pollution emissions among urban agglomerations need to be jointly managed, accelerate the process of regional integration, break "local segregation", reduce the mismatch of resource elements caused by market segmentation, establish a pollution emission trading market, and make all regions pay more attention to the overall benefits of the region. Formulate unified environmental governance standards and mutual supervision of the implementation of environmental laws and regulations between governments.

Second, the government should focus on regional advantages to promote differentiated division of labor within the region and develop characteristic industries based on local conditions. The government actively guides healthy competition in the market, promotes the appropriate development of industries in various regions of the Yangtze River Economic Belt, and improves overall resource utilization efficiency to achieve emission reduction. The regional industrial gradient transfer should be improved and 9 the upper, middle, and lower reaches of the Yangtze River Economic Belt should be optimized to save the public cost of products and reduce the waste of resources. Products from 2 various regions have achieved complementary advantages 3 via mutual competition and accelerated the upgrading of the 04 industrial structure. The leading role of the regional center 


\section{References} cooperation. interests. 44:46-55 should be acknowledged and the transformation of the regional industrial structure to a clean and green industry should be promoted.

Finally, the government should fully exploit the role of technological innovation, industrial structure optimization and economic agglomeration in the coordinated and differential development of the Yangtze River Basin. Moreover, low energy consumption and clean industries should be encouraged and promoted to form linkages in different provinces and cities and realize the effect of economic agglomeration to promote cross regional technical

Author contributions This article was planned and designed by LiXin Xiong; the research data and the model was constructed and analyzed by Jia-Jun Ning; the paper was constructed by Yun-He Dong and Meng-Meng Dai.

Competing interest The authors declare no competing financial

Funding information This work was financially supported by the National Natural Science Foundation of China (17CJY022) and the National Scholarship Foundation (202008430028).

Ethical Approval Not applicable

Consent to Participate Not applicable

Consent to Publish Not applicable

Availability of data and materials The datasets used or analysed during the current study are available from the corresponding author on reasonable request.

Azizalrahman H, Hasyimi V (2019) A Model for Urban Sector Drivers of Carbon Emissions. Sustainable Cities and Society

Baghdadi L, Martinez Zarzoso I, Zitouna H (2013) Are RTA agreements with environmental provisions reducing emissions? Journal of International Economics 90(2): 378-390

Bai JH, Wang Y, Jiang FX, Li J (2009) R\&D Element Flow, Spatial
Knowledge Spillovers and Economic Growth. Economic Research Journal 44(3):42-52

Brown WM, Dar - Brodeur A, Tweedle J (2020) Firm networks, borders, and regional economic integration. J Regional Sci 60:374-395

Dauda L, Long X, Mensah CN, Salman M (2019) The effects of economic growth and innovation on $\mathrm{CO} 2$ emissions in different regions. Environ Sci Pollut Res 26:15028-15038

Dietz T, Rosa E A (1994) Rethinking the Environmental Impacts of Population, Affluence and Technology Human Ecology Review 2(1): 277-300

Dong ZQ, Wang H (2019) Local Neighborhood Effect of Green Technology of Environmental Regulation. China Industrial Economics (01): 100-118

Dou JM, Cui SH (2018) Does domestic market integration promote the transfer of polluted industries? Industrial Economics Research (4): 76-87

Giannadaki D, Giannakis E, Pozzer A, Lelieveld J (2018) Estimating health and economic benefits of reductions in air pollution from agriculture. Science of The Total Environment $622-623$

Haken H (1983) Synergetics: An Introduction. New York: Springer - Verlag

Hasanbeigi A, Price L (2015) A technical review of emerging technologies for energy and water efficiency and pollution reduction in the textile industry. Journal of Cleaner Production 95:30-44

He XM, Lai YJ, Nie AY (2016) Regional integration and regional environmental pollution emission convergence — based on the natural experiment of the Yangtze River Delta regional integration. Soft Science 30(3):41-45

Krugman PR (1991) Increasing returns and economic geography. Journal of Political Economy 99(3): 483-499

Lanzi E, Dellink R, Chateau J (2018) The sectoral and regional economic consequences of outdoor air pollution to 2060 . Energy Economics 71:89-113

Li B, Wu S (2017) Effects of local and civil environmental regulation on green total factor productivity in China: A spatial Durbin econometric analysis. Journal of Cleaner Production 153: $342-353$

Li J, Lin B (2017) Does energy and CO2 emissions performance of China benefit from regional integration? Energy Policy 101: 366-378

83 Li L, Zeng W (2016) A Study on the Mechanism of the Impact of 
Geographical Proximity and Cognitive Proximity on the Coordinated Development of the Interprovincial Boundary Regional Economies An Empirical Analysis of the Central Delta and the Yangtze River Delta. East China Economic Management 30(05): 1 8+193

Li XS, Qi XX (2019) Analysis of Differentiated and Cooperative Development of Urban Agglomeration in the Middle Reaches of Yangtze River. Journal of Industrial Technological Economics 38(12): 75-83

Li XS, Zhang YQ Sun BW (2017) Does regional integration promote the efficiency of economic growth? an empirical analysis of the Yangtze River Economic Belt China Population. Resources and Environment 27(01): 10-19

Liu G, Yang Z, Chen B (2016) Prevention and control policy analysis for energy related regional pollution management in China. Applied Energy 166: 292-300

Liu NQ, Wu Y (2017) Can the enlargement in Yangtze River Delta boost regional economic common growth. China Industrial Economics (6):79-97

Liu XY, Yang XF, Li YX, et al (2019) Variations in dissolved inorganic carbon species in effluents from large-scale municipal wastewater treatment plants (Qingdao, China) and their potential impacts on coastal acidification. Environ Sci Pollut Res 26:15019-15027

Lu DD (2018) Conservation of the Yangtza River and sustainable development of the Yangtze River Economic Belt: An understanding of General Secretary Xi Jinping's important instructions and suggestions for their implementation. Acta Geographica Sinica 73(10): 1829-1836

Lu M, Chen Z (2009) Fragmented growth: why economic opening may worsen domestic market segmentation? Economic Research Journal 44(03):42-52

Lu M, Feng H (2014) Agglomeration and emission reduction: an empirical study on the influence of city size gap on industrial pollution intensity. The Journal of World Economy 37(07):86114

Ramanathan V, Feng Y (2009) Air pollution, greenhouse gases and climate change: Global and regional perspectives. Atmospheric Environment 43:37-50

Shao S, Zhang K, Dou JM (2019) Comparisons on the Income Measurements in Chinese Household Survey Data. Management World 35(01): 36 60+226

Shen J, Wei Y D, Yang Z (2017) The impact of environmental regulations on the location of pollution intensive industries in
China. Journal of Cleaner Production 148: 785-794

Shi D Q, Ding H, Wei P, et al (2018) Can smart city construction reduce environmental pollution. China Industrial Economics (06):117-135

Sueyoshi T, Yuan Y (2017) Social sustainability measured by intermediate approach for DEA environmental assessment: Chinese regional planning for economic development and pollution prevention. Energy Economics 66:154-166

Sun BW, Cheng ZQ (2019) Research on industrial pollution discharge mechanism of market integration: Taking the Yangtze River Economic Belt as an example China. Environmental Science 39(02):868-878

Wagner UJ, Timmins CD (2009) Agglomeration Effects in Foreign Direct Investment and the Pollution Haven Hypothesis. Environ Resource Econ 43:231-256

$\mathrm{Xu}$ HL, Deng YL (2012) Does foreign direct investment cause environmental pollution in China? Spatial measurement based on Chinese provincial panel data. Management World (02):30-43

Yan CH, Wang XH (2019) How does Financial Agglomeration Affect Green Development Efficiency? Empirical Analysis of SPDM and PTR Models Considering Spatio temporal Double Fixation. Journal of Guizhou University of Finance and Economics (01): 25-36

Yang RF (2015) Whether Industrial Agglomeration Can Reduce Environmental Pollution or Not China Population. Resources and Environment 25(02): 23-29

Yao Z, Wang F, Wang C, et al (2019) Anaerobic ammonium oxidation coupled to ferric iron reduction in the sediment of a eutrophic lake. Environ Sci Pollut Res 26:15084-15094

You JH, Chen XQ (2019) Whether regional integration cooperation leads to pollution transfer: Evidence from the enlargement of the Yangtze River Delta urban cluster China Population. Resources and Environment 29(6): 118-129

Yu BB, J G (2019) Space spillovers of Chinese urban structure adjustment and pattern selection. China Industrial Economics (01): 100-118

Yuan HX, Liu YB, Feng DY (2019) Land finance, financial development and urban expansion. Journal of Guizhou University of Finance and Economics (01): 25-36

Zhang K (2018) Is Regional integration beneficial to emission reduction? Journal of Financial Research (1):67-83

Zhang K, Shao S, Fan S (2020) Market integration and environmental quality: Evidence from the Yangtze river delta 
region of China. Journal of Environmental Management 261:

874 Zhang K, Wang DF (2014) The interaction and spatial spillover between agglomeration and pollution. China Industrial Economics (06): 70-82

877 Zhang X, Wu L, Zhang R et al (2013) Evaluating the relationships among economic growth, energy consumption, air emissions
880

881 882 883
Renewable and Sustainable Energy Reviews 18: 259-270

Zhao LD, Xu L (2019) Study on water pollution effects of regional integration based on the quasi-natural experiment of the enlargement in Yangtze River DeltaChina Population. Resources and Environment 29(03):50-61

Zhu Y, Xia Y (2019) Industrial agglomeration and environmental pollution: Evidence from China under New Urbanization. Energy \& Environment 30(06): 1010-1026 


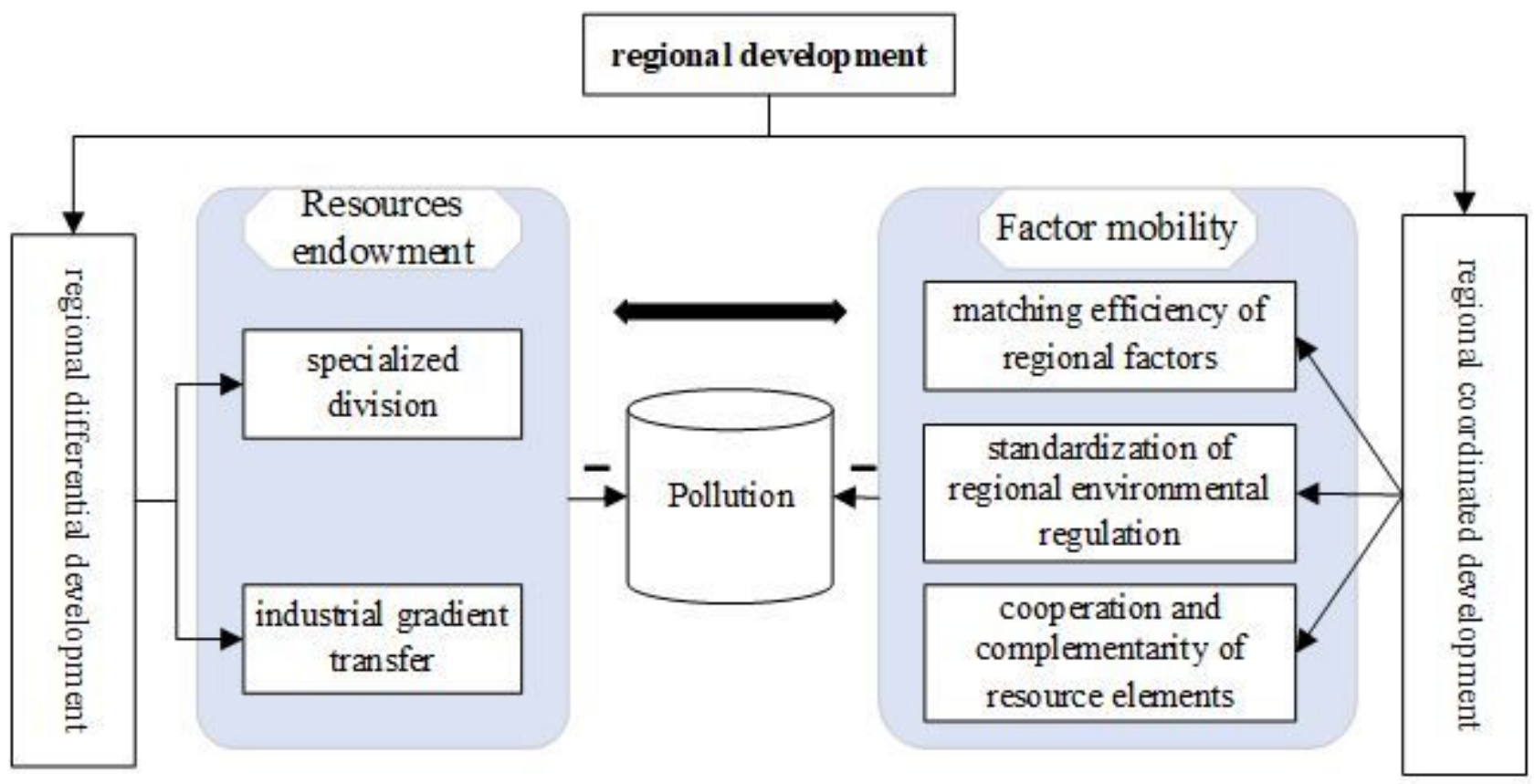

\section{Figure 1}

Regional differentiation and coordinated development of pollution emission reduction mechanisms
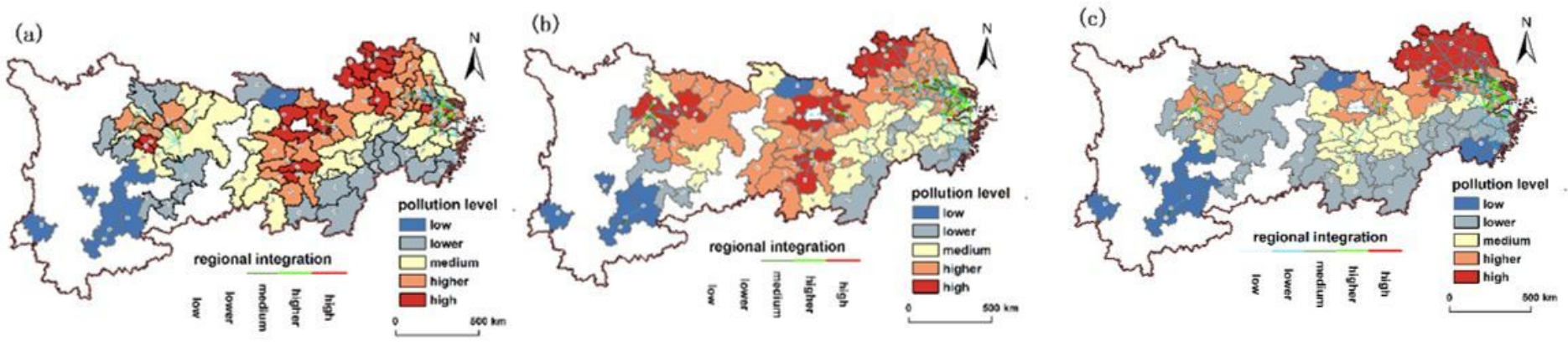

Figure 2

Spatial and temporal differentiation of pollution emissions in the coordinated development of the Yangtze Economic Belt (a: in 2008; b: in 2012; c: in 2017) Note: The designations employed and the presentation of the material on this map do not imply the expression of any opinion whatsoever on the part of Research Square concerning the legal status of any country, territory, city or area or of its authorities, or concerning the delimitation of its frontiers or boundaries. This map has been provided by the authors. 

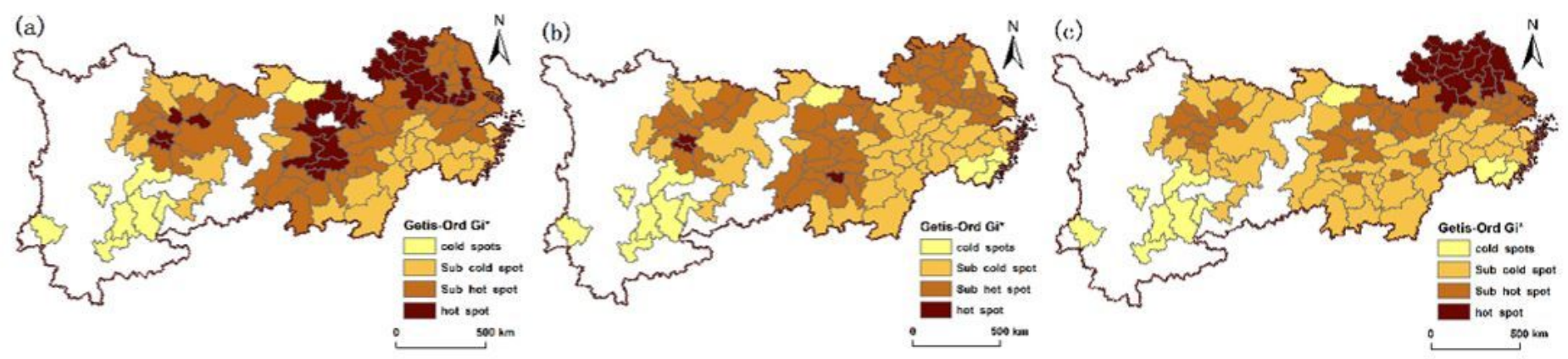

Figure 3

Spatial and temporal differentiation map of pollution concentration hotspots and cold spots cities in the Yangtze River Economic Belt is different (a: in 2008; b: in 2012; c: in 2017) Note: The designations employed and the presentation of the material on this map do not imply the expression of any opinion whatsoever on the part of Research Square concerning the legal status of any country, territory, city or area or of its authorities, or concerning the delimitation of its frontiers or boundaries. This map has been provided by the authors.

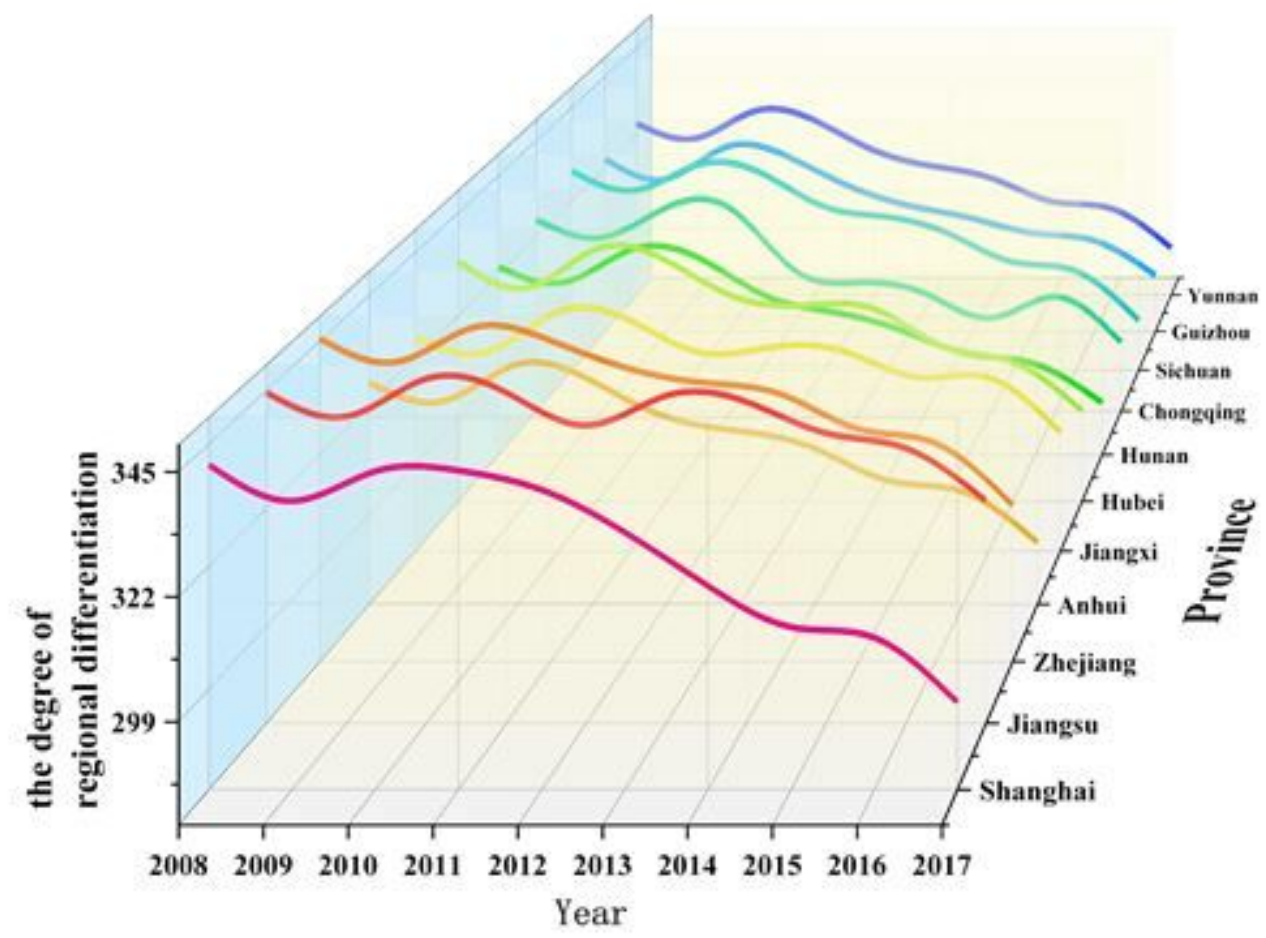

\section{Figure 4}

Development degree of different provinces and cities in the Yangtze River Economic Belt is different 


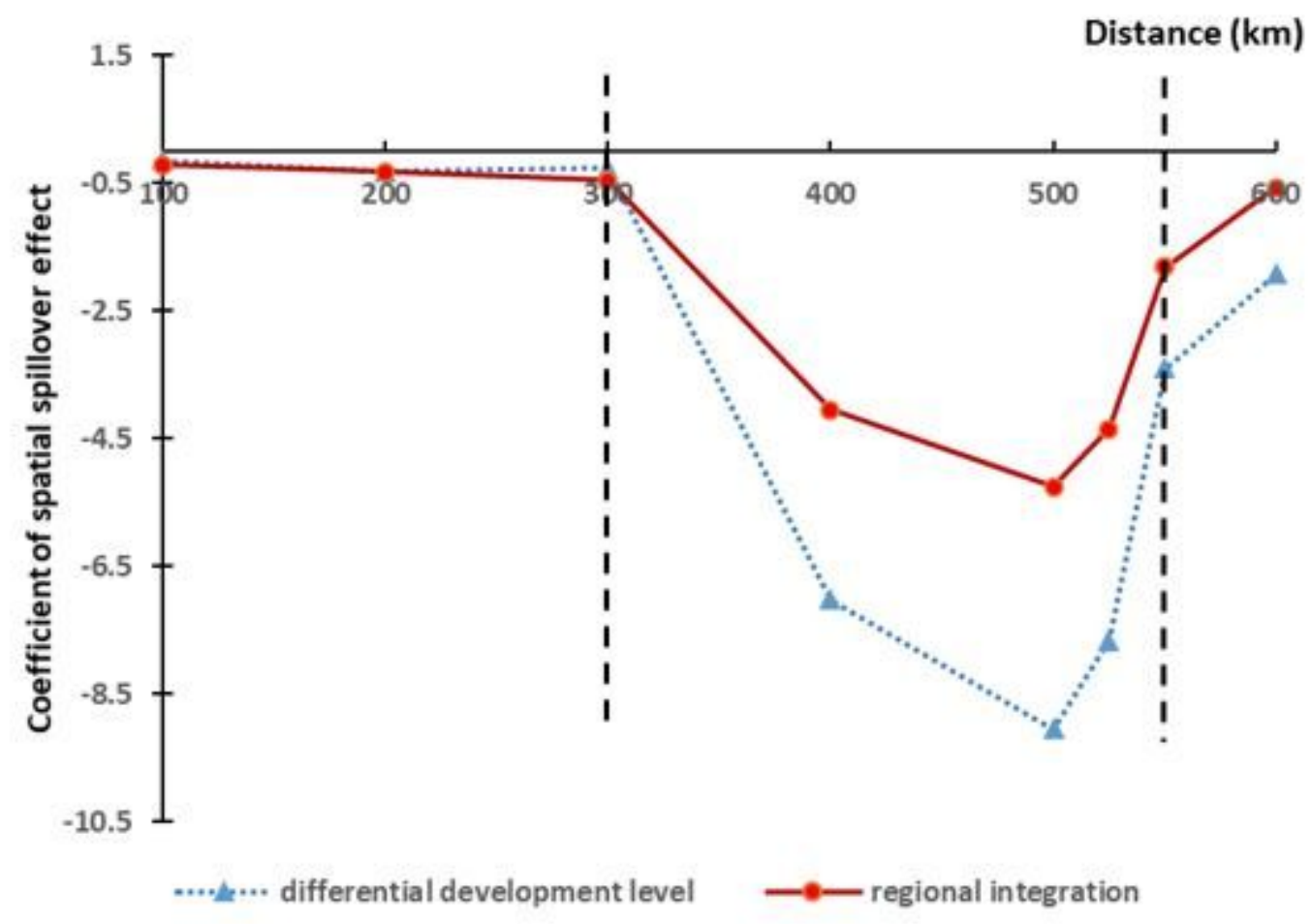

Figure 5

Spillover coefficient of differentiated coordinated development space in different urban areas 